\title{
NORMAS E PADRÕES PARA PRODUÇÃO DE BIOMASSA COMPACTADA NO MUNDO: EM BREVE O BRASIL TERÁ A SUA?
}

\author{
Igor Cassiano RANGEL ${ }^{1 *}$, Fabrício Freitas da SILVA ${ }^{1}$, Claudio Luiz Melo de SOUZA ${ }^{1,2}$, Milthon ERTHAL \\ Junior $^{1}$, Geraldo Amaral GRAVINA ${ }^{2}$ \& Aldo SHIMOYA ${ }^{1}$
}

1 Universidade Cândido Mendes, Campos dos Goytacazes, RJ, Brasil.

2 Universidade Estadual do Norte Fluminense, Campos dos Goytacazes, RJ, Brasil.

* Autor para correspondência: igorcrangel@gmail.com

DOI: http://dx.doi.org/10.18571/acbm.153

\section{RESUMO}

Neste artigo, buscou-se literatura técnico-científica que determinasse padrões de qualidade na produção de briquetes e péletes no Brasil, entretanto nada foi encontrado. Assim, realizou-se estudo para se verificar como são estabelecidos os parâmetros para esses produtos; posteriormente, realizouse uma análise em nível internacional da evolução dos mesmos. Utilizou-se a pesquisa bibliométrica para quantificar estudos recentes na área, retornando 41 trabalhos na base SCOPUS e apenas seis na base Web of Science (ISI). Dentre eles verificou-se que apenas 18 da base SCOPUS e nenhum da base ISI tinham aderência ao assunto proposto. Com isso, foi possível verificar a ausência de padrões e conformidades bem estabelecidos para a qualidade da produção brasileira, dificultando a entrada no mercado internacional, necessitando com urgência de subsídios técnico-normativos para certificação internacional.

Palavras chave: Péletes; Briquetes; Controle de Qualidade; DIN EN ISSO.

\begin{abstract}
This article propose to seek technical-scientific literature that determine quality standards in the production of briquettes and pellets, although it did not find any work concerning the theme. A study was performed to verify how the parameters for the analysis of these products are established; subsequently, an international analysis of the history and evolution of them. A bibliometric research was used to quantify recent studies in the area, which returned 41 possible papers in the SCOPUS database and only six in the Web of Science (ISI) database, of which only 18 of the SCOPUS database and none of the ISI database had adherence to the proposed subject. With this, it was possible to verify the lack of well-established standards and conformities concerning the quality of Brazilian production, making it difficult to enter the international market. It should be concluded, that, in order to be internationally certified, technical and normative subsidies for producers are urgently required.
\end{abstract}

Keywords: Pellet; Briquette; Standards and Quality Control; DIN EN ISO.

\section{Introdução}

O uso em larga escala de combustíveis fósseis tem causado grande preocupação à comunidade científica, em primeiro lugar por não serem renováveis e depois devido ao seu potencial poluidor que promove o aumento da concentração de gases de efeito estufa na atmosfera, além de, em alguns casos, terem maior custo de produção de energia renovável (GOLDEMBERG, 2009). 
De acordo com a ANEEL (2008) a biomassa é uma das mais promissoras fontes para produção de energia, com grande potencial de crescimento no Brasil nos próximos anos. Quando comparada aos combustíveis fósseis, a biomassa é capaz de produzir energia de maneira sustentável e eficiente. Somente a biomassa possui flexibilidade que possibilite o fornecimento de matéria-prima para produzir energia elétrica e biocombustíveis utilizados nos meios de transporte (CORTEZ et al., 2008).

O Painel Intergovernamental de Mudanças Climáticas (IPCC, 2012) demonstrou em seu relatório que as fontes de energia renováveis representaram 12,9\% do fornecimento mundial de energia primária no ano de 2008, a biomassa foi à maior colaboradora, sendo responsável por 10,2\% do montante, esta tem se destacado como uma das soluções possíveis, principalmente para países com grande extensão territorial como o Brasil, pois é necessário dispor de extensas áreas para plantio, a fim de que se alcance uma produção significativa (GOLDEMBERG, 2009). Há ainda a possibilidade de reaproveitamento de resíduos das agroindústrias como alternativa para a produção de energia, favorecendo a economia das mesmas, pois agrega valor a um resíduo/subproduto que ao invés de ser descartado pode gerar receita.

Os resíduos de biomassa em geral possuem baixo poder calorífico, alta umidade e baixa densidade, por isso, as indústrias brasileiras utilizam pouco esta fonte de energia, pois os custos logísticos não compensam. Por outro lado, a biomassa compactada na forma de péletes ou briquetes, não possui tais problemas, pois possuem baixa umidade, maior densidade e maior poder calorífico (OLIVEIRA, 2013).

Como as propriedades físicas, químicas e mecânicas dos briquetes e pellets são determinantes para sua qualidade, é notório que se estabeleça um conjunto de normas técnicas para definir métodos de análise e classificação dos produtos quanto as suas características físicas. Além disso, elas têm como objetivo garantir a uniformidade dos produtos, ampliando as perspectivas mercadológicas para produtores e consumidores de biocombustíveis sólidos (DIAS et al. 2012).

A legislação ou normas técnicas são criadas com a finalidade de estabelecer quais serão os procedimentos utilizados para analisar cada tipo de produto, inclusive os péletes e briquetes e, em alguns casos, estabelecer também os parâmetros técnicos de qualidade destes produtos. Estes parâmetros são criados com o propósito de garantir a uniformidade do produto final, diminuindo assim as barreiras mercadológicas ao produto, criando um mercado de biomassa compactada mais seguro, tanto para os produtores quanto para os consumidores (DIAS et al. 2012).

A demanda por péletes para uso residencial tem crescido muito nos países europeus, seja pelo menor preço relativo a lenha ou pelas comodidades oferecidas, como equipamentos com alimentação automática e uniformidade da temperatura; ou pelas diretivas da União Européia e da política dos estados membros, a fim de atingir suas metas de emissões de gases de efeito estufa (GEE) para o ano de 2020 (CARASCHI \& GARCIA, 2012).

De acordo com Caraschi \& Garcia (2012), entre 2002 e 2010, houve um crescimento na ordem de $890 \%$ no número de fábricas de péletes na Europa e na América do Norte, passando de 70 para 623 fábricas. Este crescimento no mercado de produtores de péletes tem sido acompanhado pela European Association Biomass (AEBIOM), e segundo ela, o mercado de péletes de madeira deverá consumir no ano de 2020 entre 50 e 80 milhões de toneladas, sendo necessário um sistema de comércio internacional muito mais estruturado (OLIVEIRA, 2012).

O Brasil possui grande variedade de tipos de resíduos provenientes de florestas plantadas ou nativas, da indústria madeireira e do beneficiamento de produtos agrícolas, esta diversificada fonte de resíduos vegetais, faz com que o controle de qualidade dos produtos compactados seja extremamente importante e crucial ao negócio (CORTEZ et al., 2008). Segundo Oliveira (2013), o Relatório Anual de Biocombustíveis, publicado pela União Europeia em 2013, revelou que a mesma é o maior consumidor de péletes em quantidade, atingindo a marca de 14,3 milhões de toneladas em 2012. 


\section{ACTA \\ Biomedica Brasiliensia}

Segundo o autor, estima se que na União Européia será necessária importação de 25 a 40 milhões de toneladas de biomassa para alcançar sua meta de redução da emissão de GEE em 2020.

Apesar de se produzir briquetes e péletes há muitos anos, o Brasil não possui normas específicas para análise de suas propriedades sendo comum a adaptação de normas da Associação Brasileira de Normas Técnicas (ABNT, 1981) como a NBR 6922 que trata de ensaios físicos, determinação de massa específica e densidade a granel para o carvão vegetal. Entretanto, esses métodos podem não ser aceitos no mercado externo, criando assim barreiras técnicas para as exportações brasileiras.

O Serviço Florestal Brasileiro do Ministério do Meio Ambiente (SFB/MMA) trabalha à frente do principal movimento para normatização de péletes e briquetes no Brasil, onde propõe diferentes classes de qualidade para estes produtos, baseado no teor de cinzas, utilização (industrial ou doméstica), origem dos resíduos e processo de fabricação de cada um deles. Apesar de ser um primeiro passo, trata-se ainda de uma proposta que está muito aquém do exigido pelo mercado externo (DIAS et al., 2012).

Cabe ressaltar que em 2017, foi publicado o Texto para Discussão $\mathrm{N}^{\circ} 235$ da Câmara do Senado Federal brasileiro intitulado "Pellets de madeira como uma alternativa para a geração termelétrica no Brasil”" (CUPERTINO, 2017).

O objetivo desse artigo foi copilar as principais normas de produção de biomassa compactada nos principais países produtores europeus, Estados Unidos e debater as perspectivas de normatização desse importante ativo econômico e socioambiental do agronegócio brasileiro. O embasamento do tema se deu por estudo bibliométrico em duas bases indexadoras.

\subsection{Principais Normas e Padrões no Mundo}

De acordo com Dias et al. (2012), o mercado Europeu se destaca na normatização de briquetes e péletes, com o intuito de garantir a uniformidade do produto, visando o benefício de seus consumidores. Inicialmente, essas normas foram elaboradas e implementadas isoladamente em países como Áustria, Alemanha e Suécia, porém o estabelecimento de normas individualmente acarretou em diferenças significativas em diversos parâmetros de qualidade. Isso dificultou o atendimento dos requisitos por países exportadores que visavam ao mercado europeu, por isso, o Comitê Europeu de Normalização (CEN) promoveu um movimento para uniformização das normas em todo o continente. A seguir é apresentado um breve histórico da criação das normas nos principais países consumidores e exportadores.

\subsubsection{Alemanha}

Na Alemanha, a primeira norma relativa à péletes e briquetes foi criada em 1996, pelo Instituto Alemão de Normas (Deutsches Institut fur Normung - DIN). A DIN 51731, determinava as exigências e testes para combustíveis sólidos e madeira compactada sem tratamento até 2007, quando foi complementada pela DIN EN 15270 (EN - European Norms), que estabelecia no mercado europeu as definições, exigências, testes e características dos queimadores de pellets e pequenos aquecedores.

No ano de 2002, a empresa certificadora DIN CERTCO desenvolveu parâmetros e processos descritos na norma DINPlus, baseada na DIN 51731 e na ÖNORM M 7135 da Áustria. A DINPlus estabeleceu os padrões para péletes de alta qualidade, o que favoreceu de maneira significativa o mercado de péletes para uso em aquecedores residenciais na Alemanha, sendo hoje reconhecida como a mais importante certificação mundial no que se refere à qualidade de péletes de madeira de alta qualidade. 
Visando a qualidade do produto, os parâmetros estabelecidos pelas normas na Alemanha são extremamente rigorosos com a concentração de alguns elementos químicos, estabelecendo valores máximos para eles. A norma divide os péletes em classes, de acordo com seu respectivo diâmetro, sendo obrigatória a vistoria constante e apresentação das análises realizadas no produto para receber a certificação DINPlus. É permitido o uso de material que auxilie a compactação, desde que o mesmo seja natural, em contra partida o uso de aditivo é totalmente proibido.

A DIN CERTCO é automaticamente credenciada na DIN EN ISO/IEC 17065, demonstrando que os produtos certificados DINPlus atendem a todos os requisitos das normas internacionais DIN EN ISO 17225 - 2 (referente aos péletes, Quadro 1) e DIN EN ISO 17225 - 3 (referentes aos briquetes, Quadro 2) e, em muitos casos, excedem suas exigências.

Quadro 1: Padrões de qualidade na produção de péletes na Alemanha.

\begin{tabular}{|c|c|c|}
\hline Critério & Unidade & DINplus \\
\hline \multirow[t]{2}{*}{ Diâmetro } & \multirow[t]{2}{*}{$\mathrm{mm}$} & $6,6 \pm 1,0$ \\
\hline & & $8,8 \pm 1,0$ \\
\hline Comprimento $^{1}$ & $\mathrm{~mm}$ & $3,15 \leq \mathrm{L} \leq 40,00$ \\
\hline Teor de água & $\%$ em massa & $\leq 10,0$ \\
\hline Teor de cinzas & $\%$ peso na matéria seca & $\leq 0,7$ \\
\hline Força mecânica na condição de entrega & $\%$ em massa & $\geq 97,5$ \\
\hline \multirow{2}{*}{$\begin{array}{l}\text { Fração fina no final do processo de } \\
\text { produção }{ }^{2} \text { (no último ponto de carregamento } \\
\text { anterior ao cliente) }\end{array}$} & \multirow[t]{2}{*}{$\%$ em massa } & Embalagens até $20 \mathrm{~kg}: \leq 0,5$ \\
\hline & & $\begin{array}{c}\text { Embalagens maiores e a } \\
\text { granel: } \leq 1,0\end{array}$ \\
\hline \multirow[t]{2}{*}{ Poder calórico na condição de entrega } & $\mathrm{MJ} / \mathrm{kg}$ & $\geq 16,5$ \\
\hline & $\mathrm{kWh} / \mathrm{kg}$ & $\geq 4,6$ \\
\hline Densidade aparente na fábrica (DA) & $\mathrm{kg} / \mathrm{m}^{3}$ & $600 \leq \mathrm{DA} \leq 750$ \\
\hline Auxiliar de pressão / aditivos ${ }^{3,4}$ & $\%$ em massa & $\leq 2,00$ \\
\hline Azoto & $\%$ peso na matéria seca & $\leq 0,30$ \\
\hline Enxofre & $\%$ peso na matéria seca & $\leq 0,04$ \\
\hline Cloro & $\%$ peso na matéria seca & $\leq 0,02$ \\
\hline Arsênico & $\mathrm{mg} / \mathrm{kg}$ TR & $\leq 1,00$ \\
\hline Cádmio & $\mathrm{mg} / \mathrm{kg}$ TR & $\leq 0,50$ \\
\hline Crômio & $\mathrm{mg} / \mathrm{kg} \mathrm{TR}$ & $\leq 10,0$ \\
\hline Cobre & $\mathrm{mg} / \mathrm{kg}$ TR & $\leq 10,0$ \\
\hline Levar & $\mathrm{mg} / \mathrm{kg} \mathrm{TR}$ & $\leq 10,0$ \\
\hline Mercúrio & $\mathrm{mg} / \mathrm{kg} \mathrm{TR}$ & $\leq 0,10$ \\
\hline Níquel & $\mathrm{mg} / \mathrm{kg} \mathrm{TR}$ & $\leq 10,0$ \\
\hline Zinco & $\mathrm{mg} / \mathrm{kg} \mathrm{TR}$ & $\leq 100,0$ \\
\hline Temperatura de fusão da cinza & ${ }^{\circ} \mathrm{C}$ & $\geq 1.200$ \\
\hline
\end{tabular}

Nota: 1) A quantidade de grânulos com mais de $40 \mathrm{~mm}$ pode ser de $1 \%$ (fração de massa). O comprimento máximo deve ser $\leq 45 \mathrm{~mm}$, pélete $\geq 3,15 \mathrm{~mm}$ em uma tela de furo circular e quantidade de pellets, $\mathrm{m}-\%, \geq 10 \mathrm{~mm}$; 2) partículas $\leq 3,15 \mathrm{~mm}$; 3) O auxiliar de pressão deve ser definido e deve ser de origem agrícola e/ou florestal (farinha de milho, amido de milho, farinha de centeio). Fonte: DIN CERTCO, 2015. 
Quadro 2: Padrões de qualidade na produção de briquetes na Alemanha.

\begin{tabular}{|c|c|c|}
\hline Critério & Unidade & DIN Plus briquete \\
\hline \multirow{2}{*}{ Dimensão } & $\mathrm{mm}$ & $\begin{array}{c}\text { Especificar diâmetro, largura e } \\
\text { comprimento }\end{array}$ \\
\hline & Forma & $\begin{array}{c}\text { Especificada de acordo com o } \\
\text { estabelecido pela norma }\end{array}$ \\
\hline Superfície, incluindo buraco, se houver & $\mathrm{cm}^{2} / \mathrm{Kg}$ & pode ser especificado \\
\hline Umidade & $\%$ em peso & $\leq 12$ \\
\hline Teor de cinzas $\left(550^{\circ} \mathrm{C}\right)$ & $\%$ em peso & $\leq 0,7$ \\
\hline Densidade da partícula & $\mathrm{g} / \mathrm{cm}^{3}$ & $\geq 1,0$ \\
\hline Aditivos & \% em peso da matéria seca & $\leq 2$, tipo e quantidade a indicar \\
\hline \multirow{2}{*}{ Valor Calorífico líquido } & $\mathrm{MJ} / \mathrm{kg}$ & $\geq 16,5 \mathrm{a} \geq 19,0$ \\
\hline & $\mathrm{kWh} / \mathrm{kg}$ & $\geq 4,6 \mathrm{a} \geq 5,3$ \\
\hline Durabilidade Mecânica & $\%$ em peso & $\geq 95$ \\
\hline Teor de Nitrogênio & $\%$ em peso da matéria seca & $\leq 0,30$ \\
\hline Teor de Enxofre & $\%$ em peso da matéria seca & $\leq 0,03$ \\
\hline Teor de Cloro & \% em peso da matéria seca & $\leq 0,02$ \\
\hline Teor de Arsênio & $\mathrm{mg} / \mathrm{kg}$ da matéria seca & $\leq 1,00$ \\
\hline Teor de Cádmio & $\mathrm{mg} / \mathrm{kg}$ da matéria seca & $\leq 0,50$ \\
\hline Teor de Cromo & $\mathrm{mg} / \mathrm{kg}$ da matéria seca & $\leq 10,0$ \\
\hline Teor de Cobre & $\mathrm{mg} / \mathrm{kg}$ da matéria seca & $\leq 10,0$ \\
\hline Teor de Chumbo & $\mathrm{mg} / \mathrm{kg}$ da matéria seca & $\leq 10,0$ \\
\hline Teor de Mercúrio & $\mathrm{mg} / \mathrm{kg}$ da matéria seca & $\leq 0,10$ \\
\hline Teor de Níquel & $\mathrm{mg} / \mathrm{kg}$ da matéria seca & $\leq 10,0$ \\
\hline Teor de Zinco & $\mathrm{mg} / \mathrm{kg}$ da matéria seca & $\leq 100,0$ \\
\hline
\end{tabular}

Fonte: DIN CERTCO, 2015.

\subsection{2 Áustria}

A norma ÖNORM M 7135, desenvolvida pelo Instituto Normativo Austríaco, foi publicada em 2000, quando foram estabelecidos padrões de emissão para aquecedores residenciais e o sistema de certificação de péletes. Nessa certificação, o Ministério Federal do Meio Ambiente Austríaco, permite que a matéria prima utilizada na fabricação do pélete varie de acordo com o seu uso, porém no caso do uso em aquecedores residências, autoriza apenas a madeira natural, assegurando altos padrões de qualidade do produto. A ÖNORM M 7135 determina as devidas exigências e especificações para briquetes e pellets (Quadro 3) oriundos de madeira, casca e biomassa não proveniente de madeira. Além desta, outras normas foram estabelecidas para garantir a qualidade em toda cadeia produtiva, como a ÖNORM M 7.136, que estabelece o controle de qualidade dos processos logísticos e a ÖNORM M 7.137, que determina os critérios de qualidade para os locais de armazenamento dos péletes. 
Quadro 3: Padrões de qualidade na produção de péletes e briquetes na Austria.

\begin{tabular}{|c|c|c|c|}
\hline Critério & Unidade & Pélete & Briquete \\
\hline Diâmetro & $\mathrm{mm}$ & $4-20$ & $20-120$ \\
\hline Comprimento & $\mathrm{mm}$ & máx 100 & máx 400 \\
\hline Poder calorífico & MJ / kg em massa seca & $\geq 18,0$ & $\geq 18,0$ \\
\hline Densidade & $\mathrm{kg} / \mathrm{dm}^{3}$ & $\geq 1$ & - \\
\hline Teor de cinzas & $\%$ em massa seca & $\leq 0,5$ & $\leq 6,0$ \\
\hline Teor de Umidade & $\%$ & $\leq 12$ & $\leq 18$ \\
\hline Teor de enxofre & $\%$ em massa seca & $\leq 0,04$ & $\leq 0,08$ \\
\hline Teor de cloro & $\%$ em massa seca & $\leq 0,02$ & $\leq 0,04$ \\
\hline Teor de Nitrogênio & $\%$ em massa seca & $\leq 0,3$ & $\leq 0,6$ \\
\hline Aditivos & $\%$ & \multicolumn{2}{|c|}{$<2$, somente natural } \\
\hline
\end{tabular}

Fonte: Pellets Home Website, 2017.

\subsubsection{Suécia}

A Suécia foi um dos países pioneiros a estabelecer padrões de qualidade para peletes e briquetes, sendo seu padrão, a norma SS 187120 (Swedish Standards - Padrões Suecos), estabelecido em 1999, na qual há três categorias ou grupos de péletes, de acordo com suas características, tais como diâmetro, comprimento densidade aparente, dentre outras. A norma SS 187121, criada exclusivamente para os briquetes, também, do mesmo modo, os classifica em três categorias diferentes (Quadro 4).

Quadro 4: Padrões de qualidade na produção de péletes e briquetes na Suécia.

\begin{tabular}{|c|c|c|c|c|c|c|c|}
\hline \multirow{2}{*}{ Critério } & \multirow{2}{*}{ Unidade } & \multicolumn{3}{|c|}{ Péletes } & \multicolumn{3}{|c|}{ Briquetes } \\
\hline & & Grupo 1 & Grupo 2 & Grupo 3 & Grupo 1 & Grupo 2 & Grupo 3 \\
\hline Diâmetro & $\mathrm{mm}$ & $\leq 4$ & $\leq 5$ & $\leq 6$ & $\geq 25$ & $\geq 25$ & $\geq 25$ \\
\hline Comprimento & $\mathrm{mm}$ & - & - & - & $\leq 300$ & $\leq 100$ & - \\
\hline Densidade aparente & $\mathrm{kg} / \mathrm{m}^{3}$ & $\geq 600$ & $\geq 500$ & - & $>550$ & $>450$ & $>450$ \\
\hline Finos & $\%$ & $\leq 0,8$ & $\leq 1,5$ & - & - & - & - \\
\hline Teor de umidade & $\%$ & \multicolumn{2}{|c|}{$\leq 10$} & $\leq 12$ & $\leq 12$ & $\leq 12$ & $\leq 15$ \\
\hline Teor de cinzas & $\%$ & $\leq 0,7$ & $\leq 1,5$ & $>1,5$ & $\leq 1,5$ & $\leq 1,5$ & - \\
\hline Capacidade calorífica & $\mathrm{MJ} / \mathrm{Kg}$ & $\geq 16,9$ & - & - & $\geq 16,2$ & $\geq 16,2$ & - \\
\hline Teor de enxofre & $\%$ & $\leq 0,8$ & - & - & - & - & - \\
\hline Teor de cloro & $\%$ & $<0,03$ & - & - & - & - & - \\
\hline Aditivos & & \multicolumn{3}{|c|}{ A ser acordado } & - & - & - \\
\hline
\end{tabular}

Fonte: Dias et. al., 2012.

\subsubsection{Itália}

Na Itália, a norma CTI-R04/05 (Comitato Termotecnico Italiano - Comissão Termotécnica Italiana) determina os parâmetros de qualidade dos péletes (Quadro 5), derivados de biomassa. Essa norma classifica as seguintes categorias: 1) categoria A - sem aditivo. Indicada para uso residencial, inclui biomassa compactada de tronco de árvore decídua ou conífera sem casca; madeira sem tratamento da indústria; madeira não tratada e madeira sem casca após uso; ou mistura destes materiais; 2) categoria A - com aditivo. Idem ao tópico 1, porém possibilita o uso de aditivos autorizados; 3) categoria B: péletes feitos com biomassa de resíduos agroindustriais e 4) categoria C: péletes maiores e com menor rigor nos padrões de qualidade. Além desta classificação de acordo com a composição, a CTI-R04/05 estabelece parâmetros quanto ao poder calorífico, densidade aparente, teor de cinzas, diâmetro, teor de umidade, proibição de aditivos, dentre outros. 
Quadro 5: Padrões de qualidade na produção de péletes na Itália.

\begin{tabular}{|c|c|c|c|c|c|c|c|c|}
\hline \multirow{3}{*}{$\begin{array}{l}\text { Critério } \\
\text { Diâmetro (D) }\end{array}$} & \multirow{3}{*}{$\begin{array}{c}\text { Unidade } \\
\mathrm{mm}\end{array}$} & \multicolumn{2}{|c|}{ A - sem Aditivo } & \multicolumn{2}{|c|}{ A - com Aditivo } & \multicolumn{2}{|c|}{ B } & $\mathbf{C}$ \\
\hline & & \multicolumn{4}{|c|}{$\begin{array}{l}\text { Tronco de árvore decídua ou conífera. } \\
\text { Madeira não tratada da indústria, sem } \\
\text { casca. Mistura das categorias anteriores. }\end{array}$} & \multicolumn{3}{|c|}{$\begin{array}{l}\text { Biomassa não tratada de madeiras, } \\
\text { de herbáceas, frutas e sementes, } \\
\text { bem como a mistura dessas } \\
\text { categorias. }\end{array}$} \\
\hline & & $6 \pm 0,5$ & $8 \pm 0,5$ & $6 \pm 0,5$ & $8 \pm 0,5$ & $6 \pm 0,5$ & $8 \pm 0,5$ & $\begin{array}{c}10 \pm 0,5 \leq \mathrm{D} \\
\leq 25 \pm 1,0\end{array}$ \\
\hline Comprimento (L) & $\mathrm{mm}$ & $\begin{array}{c}\mathrm{D} \leq \mathrm{L} \leq 5 \\
\mathrm{X} \mathrm{D}\end{array}$ & $\begin{array}{c}\mathrm{D} \leq \mathrm{L} \leq 4 \\
\mathrm{X} \mathrm{D}\end{array}$ & $\begin{array}{c}\mathrm{D} \leq \mathrm{L} \leq 5 \\
\mathrm{X} \mathrm{D}\end{array}$ & $\begin{array}{c}\mathrm{D} \leq \mathrm{L} \leq 4 \\
\mathrm{X} \mathrm{D}\end{array}$ & $\begin{array}{c}\mathrm{D} \leq \mathrm{L} \leq 5 \\
\mathrm{X} \mathrm{D}\end{array}$ & $\begin{array}{c}\mathrm{D} \leq \mathrm{L} \leq 4 \\
\mathrm{X} \mathrm{D}\end{array}$ & $\begin{array}{c}\mathrm{D} \leq \mathrm{L} \leq 4 \\
\mathrm{X} \mathrm{D}\end{array}$ \\
\hline Umidade & $\%$ peso & \multicolumn{2}{|c|}{$\leq 10$} & \multicolumn{2}{|c|}{$\leq 10$} & \multicolumn{2}{|c|}{$\leq 10$} & $\leq 15$ \\
\hline Cinza & $\begin{array}{l}\% \text { peso na } \\
\text { matéria seca }\end{array}$ & \multicolumn{2}{|c|}{$\leq 0,7$} & \multicolumn{2}{|c|}{$\leq 0,7$} & \multicolumn{2}{|c|}{$\leq 1,5$} & $\begin{array}{c}\text { Especificar } \\
\text { o valor }\end{array}$ \\
\hline $\begin{array}{l}\text { Durabilidade } \\
\text { Mecânica }\end{array}$ & $\%$ peso & \multicolumn{2}{|c|}{$\geq 97,7$} & \multicolumn{2}{|c|}{$\geq 97,7$} & \multicolumn{2}{|c|}{$\geq 95,0$} & $\geq 90,0$ \\
\hline Finos & $\%$ peso & \multicolumn{2}{|c|}{$\leq 1,0$} & \multicolumn{2}{|c|}{$\leq 1,0$} & \multicolumn{2}{|c|}{$\leq 1,0$} & $\begin{array}{c}\text { Especificar } \\
\text { o valor }\end{array}$ \\
\hline Aditivo & $\begin{array}{c}\% \text { peso } \\
\text { prensado }\end{array}$ & \multicolumn{2}{|c|}{ Proibido } & \multicolumn{2}{|c|}{$\begin{array}{c}\text { Especificar tipo e } \\
\text { quantidade }\end{array}$} & \multicolumn{2}{|c|}{$\begin{array}{c}\text { Especificar tipo e } \\
\text { quantidade }\end{array}$} & $\begin{array}{l}\text { Especificar } \\
\text { quantidade }\end{array}$ \\
\hline Azoto & $\begin{array}{l}\% \text { peso na } \\
\text { matéria seca }\end{array}$ & \multicolumn{2}{|c|}{$\leq 0,3$} & \multicolumn{2}{|c|}{$\leq 0,3$} & \multicolumn{2}{|c|}{$\leq 0,3$} & $\begin{array}{l}\text { Especificar } \\
\text { o valor }\end{array}$ \\
\hline Cloro & $\begin{array}{l}\% \text { peso na } \\
\text { matéria seca }\end{array}$ & \multicolumn{2}{|c|}{$\leq 0,03$} & \multicolumn{2}{|c|}{$\leq 0,03$} & \multicolumn{2}{|c|}{ Especificar o valor } & $\begin{array}{c}\text { Especificar } \\
\text { o valor }\end{array}$ \\
\hline Enxofre & $\begin{array}{c}\% \text { peso na } \\
\text { matéria seca }\end{array}$ & \multicolumn{2}{|c|}{$\leq 0,05$} & \multicolumn{2}{|c|}{$\leq 0,05$} & \multicolumn{2}{|c|}{$\leq 0,05$} & $\begin{array}{c}\text { Especificar } \\
\text { o valor }\end{array}$ \\
\hline $\begin{array}{l}\text { Densidade } \\
\text { Aparente }\end{array}$ & $\mathrm{Kg} / \mathrm{m}^{3}$ & \multicolumn{2}{|c|}{$620 \leq \mathrm{DA} \leq 720$} & \multicolumn{2}{|c|}{$620 \leq \mathrm{DA} \leq 720$} & \multicolumn{2}{|c|}{$600 \leq \mathrm{DA} \leq 720$} & $\geq 550$ \\
\hline Poder Calorífico & $\begin{array}{c}\mathrm{MJ} / \mathrm{kg} \\
(\mathrm{kcal} / \mathrm{kg})\end{array}$ & \multicolumn{2}{|c|}{$\begin{array}{c}\geq 16,9 \\
(\geq 4039)\end{array}$} & \multicolumn{2}{|c|}{$\begin{array}{c}\geq 16,9 \\
(\geq 4039)\end{array}$} & \multicolumn{2}{|c|}{$\begin{aligned} & \geq 16,2 \\
&(\geq 3870)\end{aligned}$} & $\begin{array}{c}\text { Especificar } \\
\text { o valor }\end{array}$ \\
\hline
\end{tabular}

Fonte: Comitato Termotecnico Italiano, 2004.

\subsubsection{França}

A França não possui uma norma oficial para pellets e briquetes de madeira, porém, com o intuito de proteger o consumidor final, estabeleceu um controle de qualidade efetuado pela International Association of Bioenergy Professionnals (ITEBE) - Associação Internacional de Profissionais Liberais da Bioenergia - que classifica péletes e briquetes de acordo com o tipo de equipamento em que serão utilizados, tais como fogões, caldeiras, caldeiras grandes ou incineradores, tal como apresentado no Quadro 6. 
Quadro 6: Padrões de qualidade na produção de péletes na França.

\begin{tabular}{|l|c|c|c|c|}
\hline Critério & Unidade & Fogão & Caldeira & Caldeira Grande/Incinerador \\
\hline Diâmetro & $\mathrm{mm}$ & $6 \pm 1$ & $8-10 \pm 1$ & $>16$ \\
\hline Comprimento & $\mathrm{mm}$ & $10-30$ & $10-15$ & $>16$ \\
\hline Densidade aparente & $\mathrm{kg} / \mathrm{m}^{3}$ & \multicolumn{2}{|c|}{$>650$} & - \\
\hline Densidade da unidade & $\mathrm{kg} / \mathrm{dm}^{3}$ & \multicolumn{2}{|c|}{$1,2-1,4$} & - \\
\hline Teor de umidade & $\%$ & \multicolumn{2}{|c|}{$<10$} & - \\
\hline Teor de cinzas & $\%$ & \multicolumn{2}{|c|}{$<10$} & - \\
\hline Capacidade calorífica & $\mathrm{MJ} / \mathrm{Kg}$ & \multicolumn{2}{|c|}{$>4052$} & - \\
\hline Teor de Enxofre & $\%$ & \multicolumn{2}{|c|}{$<0,08$} & - \\
\hline Teor de Nitrogênio & $\%$ & \multicolumn{2}{|c|}{$<0,3$} & - \\
\hline Teor de Cloro & $\%$ & $<0,3$ & - & - \\
\hline Teor de Sódio & $\mathrm{ppm}$ & $<300$ & - & - \\
\hline
\end{tabular}

Fonte: Garcia Maraver e Perez Jimenez, 2015.

\subsubsection{Padronização Europeia}

Devido à grande variedade de normas no mercado Europeu, foi criado um movimento com a intenção de unificar as normas existentes em apenas uma, para isso, o European Committee for Standardisation (CEN) - Comitê Europeu de Normalização - recebeu um mandato para desenvolvimento de normas para combustíveis sólidos, incluindo parâmetros e orientações pertinentes à densidade das partículas, teor de umidade, diâmetro da partícula, comprimento da partícula, teor de cinzas, poder calorífico, entre outros (Dias et al., 2012).

No ano de 2010, a empresa Deutsches Pelletinstitut (DEPI) criou a marca de certificadora internacional ENplus ${ }^{\circledR}$, que estabelece rigorosos limites em toda cadeia de fornecimento e produção de péletes e briquetes, desde o processo de peletização até a entrega final ao cliente, promovendo assim uma qualidade superior, conforme descrito nos Quadros 7 e 8. A propriedade da marca ENplus ${ }^{\circledR}$ é da Associação Europeia de Biomassa (AEBIOM), que é integrada também pelo Conselho de Pellet Europeu (EPC). A ENplus ${ }^{\circledR}$ foi introduzida primeiramente na Alemanha, no ano de 2010, tendo um crescimento muito rápido por toda Europa. Em 2016 atingiu a marca de 41 países certificados em 5 continentes diferentes, atingindo uma produção de mais de 6 milhões de toneladas de pellets ENplus $^{\circledR}$. Os requisitos de qualidade da ENplus ${ }^{\circledR}$ se baseiam na ISO 17225 - 2, para produção de péletes e na ISO 17225 - 3 para produção de briquetes, que são padrões internacionais, se desvencilhando das normas europeias. O certificado ENplus ${ }^{\circledR}$ possui critérios que vão além dos exigidos pela ISO, conferindo a este selo qualidade no produto sem haver grandes emissões e aquecimento, apesar do alto valor energético.

Devido à necessidade de se internacionalizar, não só a certificação, mas também os padrões de qualidade, criou-se a DIN EN ISO 17225 - 2 (para péletes) e DIN EN ISO 17225 - 3 (para briquetes), que estabelece uma séries de normas internacionais a serem utilizadas no controle de qualidade de toda biomassa compactada que recebe certificação DIN Plus e/ou ENplus ${ }^{\circledR}$. As normas utilizadas para combustíveis sólidos e suas respectivas determinações são apresentadas a seguir: ISO 16948: Determinação do teor total de carbono, hidrogênio e nitrogênio do conteúdo; ISO 16968: Determinação de elementos menores; ISO 16994: Determinação do teor total de enxofre e cloro; ISO 17828: Determinação da densidade aparente; ISO 17829: Determinação do comprimento e diâmetro das pastilhas; ISO 17831-1: Determinação da durabilidade mecânica; ISO 18122: Determinação do conteúdo de cinzas; ISO 18125: Determinação do poder calorífico; ISO 18134: Determinação do teor de umidade; ISO 18846: Determinação de finos em quantidade de grânulos; CEN/TC 15370-1: Determinação do comportamento de fusão das cinzas. 
Quadro 7: Padrões de qualidade na produção de péletes, certificação ENplus ${ }^{\circledR}$

\begin{tabular}{|c|c|c|c|c|}
\hline Propriedade & Unidade & EN plus A1 & EN plus A2 & EN plus B \\
\hline Diâmetro & $\mathrm{mm}$ & \multicolumn{3}{|c|}{$6,0 \pm 1,0$ ou $8,0 \pm 1,0$} \\
\hline Comprimento & $\mathrm{mm}$ & \multicolumn{3}{|c|}{$3,15<\mathrm{L} \leq 40^{4}$} \\
\hline Umidade & $\%$ do Peso $^{2}$ & \multicolumn{3}{|c|}{$\leq 10$} \\
\hline Cinza $^{1}$ & $\%$ do Peso ${ }^{3}$ & $\leq 0,7$ & $\leq 1,2$ & $\leq 2,0$ \\
\hline Durabilidade Mecânica & $\%$ do Peso $^{2}$ & $\geq 98,0^{5}$ & \multicolumn{2}{|c|}{$\geq 97,5^{5}$} \\
\hline Quant particulas $(<3,15 \mathrm{~mm})$ & $\%$ do Peso $^{2}$ & \multicolumn{3}{|c|}{$\leq 1,0_{6}(\leq 0,5)^{7}$} \\
\hline Temperatura de pellets & ${ }^{\circ} \mathrm{C}$ & \multicolumn{3}{|c|}{$\leq 40^{8}$} \\
\hline Valor Calorífico Líquido & $\mathrm{KWh} / \mathrm{kg}{ }^{2}$ & \multicolumn{3}{|c|}{$\geq 4,6^{9}$} \\
\hline Densidade Aparente & $\mathrm{Kg} / \mathrm{m}^{3}{ }^{2}$ & \multicolumn{3}{|c|}{$600 \leq \mathrm{BD} \leq 750$} \\
\hline Aditivos & $\%$ do Peso $^{2}$ & \multicolumn{3}{|c|}{$\leq 2,0^{10}$} \\
\hline Azoto & $\%$ do Peso ${ }^{3}$ & $\leq 0,3$ & $\leq 0,5$ & $\leq 1,0$ \\
\hline Enxofre & $\%$ do Peso ${ }^{3}$ & $\leq 0,04$ & \multicolumn{2}{|c|}{$\leq 0,05$} \\
\hline Cloro & $\%$ do Peso $^{3}$ & \multicolumn{2}{|c|}{$\leq 0,02$} & $\leq 0,03$ \\
\hline Temperatura de Deformação de Cinza 1 1) & ${ }^{\circ} \mathrm{C}$ & $\geq 1200$ & \multicolumn{2}{|c|}{$\geq 1100$} \\
\hline Arsênio & $\mathrm{Mg} / \mathrm{Kg}^{3}$ & \multicolumn{3}{|c|}{$\leq 1,0$} \\
\hline Cádmio & $\mathrm{Mg} / \mathrm{Kg}^{3}$ & \multicolumn{3}{|c|}{$\leq 0,5$} \\
\hline Cromo & $\mathrm{Mg} / \mathrm{Kg}^{3}$ & \multicolumn{3}{|c|}{$\leq 10$} \\
\hline Cobre & $\mathrm{Mg} / \mathrm{Kg}^{3}$ & \multicolumn{3}{|c|}{$\leq 10$} \\
\hline Chumbo & $\mathrm{Mg} / \mathrm{Kg}^{3}$ & \multicolumn{3}{|c|}{$\leq 10$} \\
\hline Mercúrio & $\mathrm{Mg} / \mathrm{Kg}^{3}$ & \multicolumn{3}{|c|}{$\leq 0,1$} \\
\hline Níquel & $\mathrm{Mg} / \mathrm{Kg}^{3}$ & \multicolumn{3}{|c|}{$\leq 10$} \\
\hline Zinco & $\mathrm{Mg} / \mathrm{Kg}^{3}$ & \multicolumn{3}{|c|}{$<100$} \\
\hline
\end{tabular}

Nota: 1- a cinza é produzida à $815^{\circ} \mathrm{C} ; 2$ - conforme recebido; 3 - base seca. 4 - no máximo de $1 \%$ dos peletes podem ser superiores a $40 \mathrm{~mm}$, não são permitidas pastilhas superiores a $45 \mathrm{~mm} ; 5$ - na unidade de transporte (caminhão, embarcação, etc) no local de produção; 6- no portão da fábrica ou ao carregar o caminhão para entregas aos usuários finais; 7- no portão da fábrica, ao encher sacos de pelotas ou sacos grandes selados; 8- no último ponto de carregamento para entregas de caminhões aos usuários finais; 9 - igual $\geq 16,5 \mathrm{MJ} / \mathrm{Kg}$ como recebido; 10 - a quantidade de aditivos na produção deve ser limitada a $1,8 \%$, a quantidade de pós-produção, os aditivos como óleos de revestimento devem ser limitados a 0,2 \% em peso dos grânulos. Fonte: European Pellet Council; Associação Européia de Biomassa, 2015. 
Quadro 8: Padrões de qualidade na produção de briquetes, certificação ENplus ${ }^{\circledR}$

\begin{tabular}{|c|c|c|c|}
\hline Propriedade & Unidade & EN plus A1 & EN plus A2 \\
\hline Umidade & $\%$ do Peso ${ }^{b}$ & $\leq 12$ & $\leq 15$ \\
\hline Conteúdo de cinzas & $\%$ do Peso $^{a}$ & $\leq 1,0$ & $\leq 1,5$ \\
\hline Densidade de partículas & $\mathrm{g} / \mathrm{cm}^{3 \mathrm{~b}}$ & $\geq 1,0$ & $\geq 0,9$ \\
\hline Valor calórico & $\mathrm{MJ} / \mathrm{kg}^{\mathrm{b}}(\mathrm{kWh} / \mathrm{kg})$ & $\geq 15,5(\geq 4,3)$ & $\geq 15,3(\geq 4,25)$ \\
\hline Azoto & $\%$ do Peso $^{\mathrm{a}}$ & $\leq 0,3$ & $\leq 0,5$ \\
\hline Enxofre & $\%$ do Peso ${ }^{a}$ & $\leq 0,04$ & $\leq 0,04$ \\
\hline Cloreto & $\%$ do Peso $^{a}$ & $\leq 0,02$ & $\leq 0,02$ \\
\hline Arsênico & $\mathrm{mg} / \mathrm{kg}^{\mathrm{a}}$ & \multicolumn{2}{|c|}{$\leq 1$} \\
\hline Cádmio & $\mathrm{mg} / \mathrm{kg}^{\mathrm{a}}$ & \multicolumn{2}{|c|}{$\leq 0,5$} \\
\hline Cromo & $\mathrm{mg} / \mathrm{kg}^{\mathrm{a}}$ & \multicolumn{2}{|c|}{$\leq 10$} \\
\hline Cobre & $\mathrm{mg} / \mathrm{kg}^{\mathrm{a}}$ & \multicolumn{2}{|c|}{$\leq 10$} \\
\hline Conduzir & $\mathrm{mg} / \mathrm{kg}^{\mathrm{a}}$ & \multicolumn{2}{|c|}{$\leq 10$} \\
\hline Mercúrio & $\mathrm{mg} / \mathrm{kg}^{\mathrm{a}}$ & \multicolumn{2}{|c|}{$\leq 0,1$} \\
\hline Níquel & $\mathrm{mg} / \mathrm{kg}^{\mathrm{a}}$ & \multicolumn{2}{|c|}{$\leq 10$} \\
\hline Zinco & $\mathrm{mg} / \mathrm{kg}^{\mathrm{a}}$ & \multicolumn{2}{|c|}{$\leq 100$} \\
\hline
\end{tabular}

\subsubsection{Estados Unidos}

Desde 1995, o Pellet Fuel Institute (PFI) estabelece padrões e diretrizes para combustíveis de biomassa compactada nos Estados Unidos, cabendo aos produtores de péletes e briquetes a garantia da qualidade do produto de acordo com as características registradas na rotulagem. Os padrões estabelecidos pelo PFI determinam as especificações para uso doméstico e industrial, sem fazer discriminação quanto a briquetes e péletes, porém quanto a sua caracterização, a PFI propõe a utilização de algumas normas específicas da American Society for Testing and Materials (ASTM) Sociedade Americana para Testes e Materiais.

Quadro 9: Padrões de qualidade na produção de acordo com o Pellet Fuel Institute (PFI)

\begin{tabular}{|l|c|c|c|c|}
\hline \multicolumn{1}{|c|}{ Critério } & Unidade & Premium & Standard & Utility \\
\hline Densidade aparente & lb./ pé cúbico & $40,0-48,0$ & $38,0-48,0$ & $38,0-48,0$ \\
\hline Diâmetro & polegadas & $0,230-0,285$ & $0,230-0,285$ & $0,230-0,285$ \\
\hline Diâmetro & mm & $5,84-7,25$ & $5,84-7,25$ & $5,84-7,25$ \\
\hline Índice de durabilidade das pastilhas & $\%$ & $\geq 96,5$ & $\geq 95,0$ & $\geq 95,0$ \\
\hline Finos (no portão da empresa) & $\%$ & $\leq 0,50$ & $\leq 1,0$ & $\leq 1,0$ \\
\hline Cinza inorgânica & $\%$ & $\leq 1,0$ & $\leq 2,0$ & $\leq 6,0$ \\
\hline Comprimento (> 1,50 polegadas) & $\%$ & $\leq 1,0$ & $\leq 1,0$ & $\leq 1,0$ \\
\hline Umidade & $\%$ & $\leq 8,0$ & $\leq 10,0$ & $\leq 10,0$ \\
\hline Cloreto & ppm & $\leq 300$ & $\leq 300$ & $\leq 300$ \\
\hline Valor de aquecimento & & N/A & N/A & N/A \\
\hline Fusão da cinza & & N/A & N/A & N/A \\
\hline
\end{tabular}

Fonte: Pellet Fuels Institute Website, 2017 


\section{Biomedica Brasiliensia}

ISSN: 2236-0867

\section{Metodologia}

A Bibliometria é o estudo por métodos e técnicas para estabelecer métricas em documentos e informações, sempre com o intuito de associar a estatística à pesquisa bibliográfica (HOOD \& WILSON, 2001). Este trabalho baseou-se no modelo proposto por Costa (2010), sendo a pesquisa realizada em Scopus e Web of Science (ISI), devido sua abrangência e natureza de indexação.

No primeiro instante, buscou-se delimitar o produto, ou seja, o pélete e o briquete. Neste caso, utilizou-se do elemento conetivo "OR" para uni-los, adotando os termos "pellet or briquette" do idioma Inglês, como referencia ao produto. Em sequencia, buscou-se delimitar a questão, que neste caso seria a criação de normas e/ou padrões de certificação para briquetes ou péletes. Os termos "Standards", "Certification" e "Certification Standards", foram pesquisados, mas como são termos que se sobrepõem, optou-se por "Standards", pelo fato de ter retornado maior número de artigos relacionados, seja individualmente ou com o termo conectivo "AND" com mais um dos outros dois termos selecionados. Por fim, delimitou-se o momento da cadeia produtiva em que estas normas atuariam, sendo definido a fase de produção como a mais indicada. Para isso, dois termos foram consultados "Production Control" e "Quality Control", que são usados como sinônimos, e escolheu se aquele que retornou maior número de artigos relacionados, "Quality Control".

Estabeleceu-se então os termos de busca "pellet or briquette", "Standards" e "Quality Control", que foram pesquisados individualmente e pareados, utilizando o termo conectivo " $A N D$ ", e por fim, os três termos em conjunto. No resultado da pesquisa em que se utilizou os três termos, foi feito um corte temporal, restringindo aos dez anos recentes (2008 - 2017) e posteriormente delimitouse também a área de concentração.

\section{Resultados e Discussão}

A pesquisa iniciou-se com a busca de cada um dos termos individualmente, desta forma o termo "briquette or pellet" retornou 76.224 e 24.228 artigos, o termo "quality control" 328.624 e 425.449 artigos e o termo "Standards" 2.748 .721 e 1.523 .378 artigos, para as bases SCOPUS e ISI, respectivamente (Figura 1).

Em seguida, a combinação destes termos, com o uso do conectivo "AND", a combinação "briquette or pellet and Quality control" facultou em uma redução abrupta no número de artigos, sendo encontrados 509 na base SCOPUS e 71 na base ISI. Esta redução de artigos, com menor severidade, também foi percebida nas outras duas combinações, de maneira que a combinação dos termos "briquette or pellet and standards" apresentou 3.901 artigos na base SCOPUS e 192 na base ISI e a combinação dos termos "standards and Quality control" resultou em 67.687 artigos na base SCOPUS e 3.980 na base ISI. 
SCOPUS

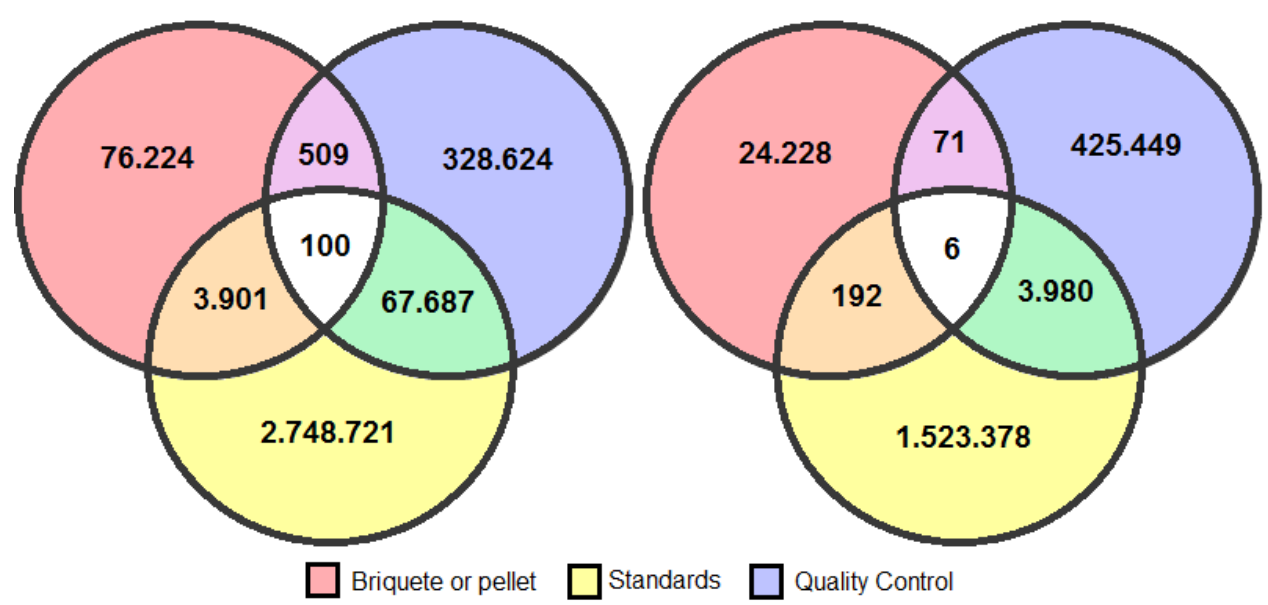

Figura 1: Registros indexados com os termos pesquisados nas bases SCOPUS e ISI.

Por fim, a combinação dos três termos "briquette or pellet and standards and Quality control" resultou em 100 artigos na base SCOPUS e apenas 6 artigos na base ISI (Figura 1). Para refinamento dos registros da base SCOPUS, realizou-se corte temporal para evitar artigos defasados, considerando apropriados os artigos desde 2008, o que eliminou 62 artigos na base SCOPUS. Isto não foi realizado para a base ISI, devido ao baixo número de registros.

Para os artigos remanescentes, observou-se grande diversidade quanto às áreas de concentração, isso se deve ao fato da utilização de péletes e briquetes em inúmeras aplicações. Para evitar isso, delimitou-se a pesquisa nas seguintes áreas de concentração: Ciências Agrícolas e Biológicas, Bioquímica, Genética e Biologia Molecular, Energia, Engenharia e Ciência Ambiental, isto reduziu o número de artigos na base SCOPUS para 41 artigos. A partir destes artigos, buscou-se mensurar o ano de publicação, autores que mais publicaram, países que mais promovem publicações na área, quais periódicos possuem maior número de artigos relacionados, quais tipos de trabalho são desenvolvidos e em quais áreas do conhecimento os artigos selecionados se encontram.

Os dados obtidos foram dispostos de forma a mostrar o número de publicações ocorridas em cada um dos anos analisados (Figura 2), onde podemos notar pouca variação no número de publicações até o ano de 2016, quando houve significativo aumento, atingindo a marca de nove artigos. O ano de 2017 mostrou-se atípico por em outubro, quando realizada a pesquisa, ainda não havia nenhum registro na base SCOPUS. 


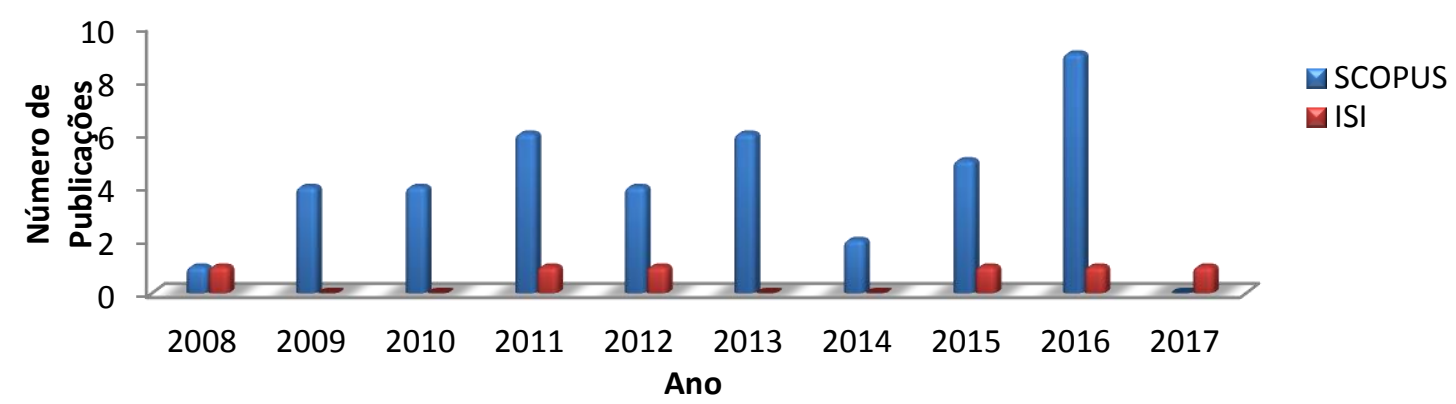

Figura 2. Registros indexados em cada uma das bases SCOPUS e ISI.

Devido a grande diferença na quantidade de artigos selecionados em cada uma das bases, a comparação entre elas foi discrepante (Figura 3), onde na base SCOPUS as áreas de conhecimento Ciências Agrícolas e Biológicas, Bioquímica e Energia são as áreas que apresentam maior número de publicações, com doze cada uma delas, enquanto na base ISI a área de química é a única que se destaca, com quatro publicações.

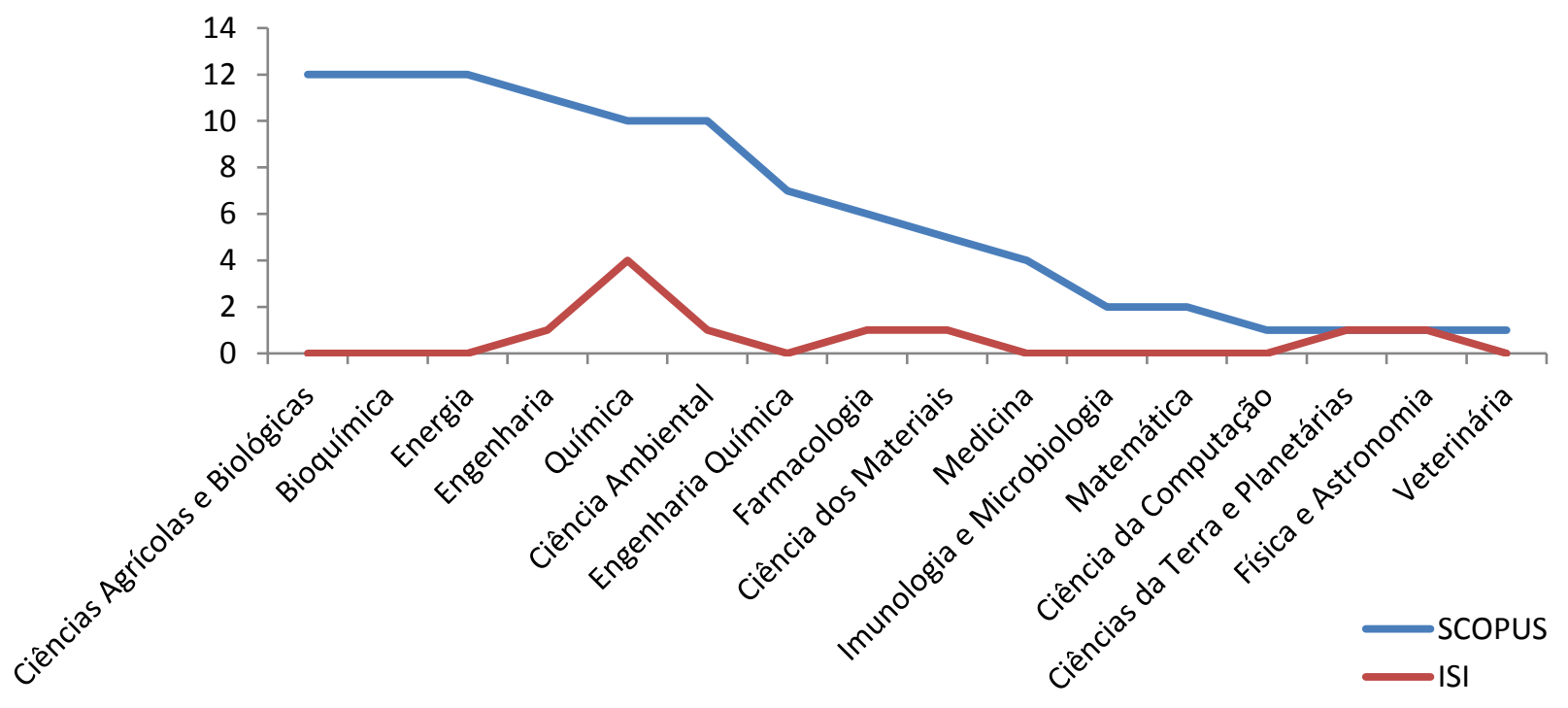

Figura 3: Número de registros por área de conhecimento.

Quanto aos autores ou pesquisadores que mais publicaram na área, observou-se que apenas um tem três registros, seguido por seis autores com dois e os demais (161) com apenas um artigo. Outro fato, que chama atenção, é que não há um autor que tenha publicado em ambas as bases. Os principais autores estão selecionados no Quadro 10. Dos 47 artigos que a pesquisa retornou, 35 eram artigo científico, sendo 30 na base SCOPUS e 5 na ISI; 9 documentos de conferencia, com 8 na base SCOPUS e 1 na ISI e 3 revisões, todas na base SCOPUS.

Quando se quantifica o número de publicações em relação ao país, é notório o quão o Brasil está atrasado na formulação de normas e padronização na sua produção de péletes e briquetes. $\mathrm{Na}$ Figura 4, observa se que a Alemanha, pioneira na implantação de normas de produção e certificação de péletes na Europa, com seis artigos publicados, seguida por Áustria e Bélgica com cinco artigos e República Checa e Estados Unidos, ambos com quatro artigos. O Brasil, nestes dez anos que a pesquisa engloba, publicou apenas dois artigos na base SCOPUS e nenhum na base ISI. Fato 


\section{ACTA \\ Biomedica Brasiliensia}

ISSN: 2236-0867

lamentável, uma vez que a biomassa no Brasil já é responsável por mais de 59\% da oferta de energia renovável desde 2014 e o potencial para geração de energia por meio de biomassa é de 1,5 milhão de kW por ano (Cupertino, 2017). Ademais, identificamos que o Brasil já possui na Região Sul, 18 empresas compactadoras de biomassa certificadas pela ENplus (www.enplus-pellets.eu).

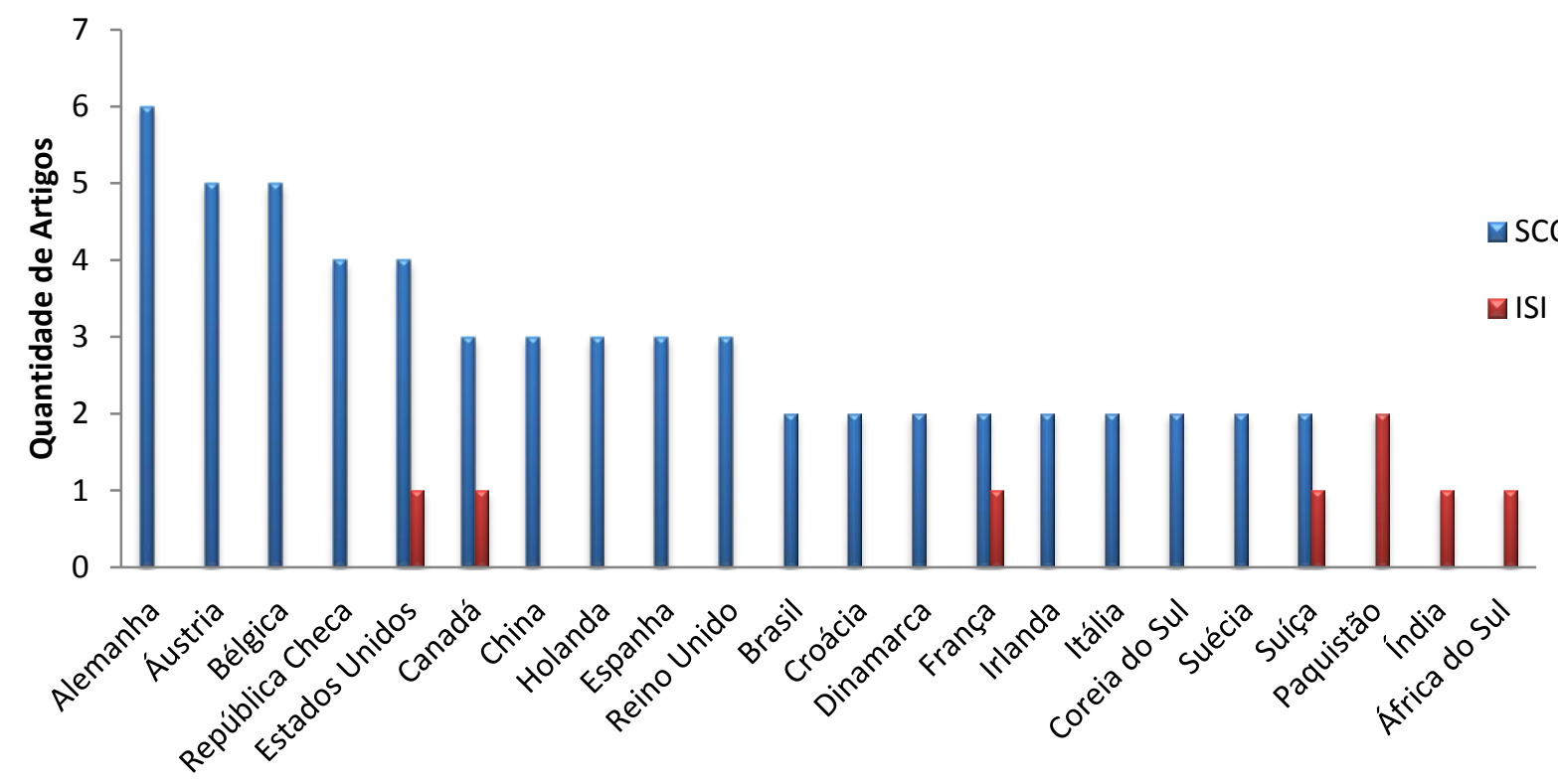

Figura 4: Países que mais publicaram nas bases SCOPUS e ISI.

Posteriormente, verificou-se a concordância do assunto abordado nos artigos com o tema da pesquisa, avaliando a aderência e a atualidade. Este processo de seleção descartou todos os artigos encontrados na base ISI e 23 artigos, dos 41 na base SCOPUS. Este grande número de artigos descartados se deve ao vasto uso da tecnologia de péletes e briquetes, como na indústria química, farmacêutica e médica. Dentre os 18 artigos selecionados a maioria trata de algum ponto específico das normas já estabelecidas ou do controle de qualidade propriamente dito, sendo poucos que trabalham com essa questão da necessidade das normas de maneira mais enfática. Os artigos selecionados estão apresentados no Quadro 10. O artigo de Garcia-Maraver et al. (2014) chama a atenção pelo número de citações (40) superior e por comparar a emissão de gases e particulados de pelletes usados em queimadores residenciais considerando o tipo de biomassa de origem. 
Quadro 10: Publicações com abordagem da qualidade de biomassa compactada.

\begin{tabular}{|c|c|c|c|c|c|}
\hline Item & Autor & Título & Periódico & Ano & $\mathbf{N}^{\mathbf{o}}$ \\
\hline 1 & $\begin{array}{l}\text { Krigstin S., Wetzel S., } \\
\text { Mabee W., Stadnyk S. }\end{array}$ & $\begin{array}{l}\text { Can woody biomass support a pellet industry in } \\
\text { southeastern Ontario: A case study. }\end{array}$ & Forestry Chronicle & 2016 & 0 \\
\hline 2 & $\begin{array}{l}\text { Brunerova A., Ivanova } \\
\text { T., Brozek M. }\end{array}$ & $\begin{array}{l}\text { Mechanical durability of digestate briquettes } \\
\text { mixed with mineral additives. }\end{array}$ & $\begin{array}{l}\text { Engineering for Rural } \\
\text { Development }\end{array}$ & 2016 & 0 \\
\hline 3 & $\begin{array}{l}\text { Brunerová A., Pecen J., } \\
\text { Brožek M., Ivanova T. }\end{array}$ & $\begin{array}{l}\text { Mechanical durability of briquettes from } \\
\text { digestate in different storage conditions. }\end{array}$ & Agronomy Research & 2016 & 3 \\
\hline 4 & $\begin{array}{l}\text { Lv F., Wang H., Kong } \\
\text { D., Chen X., Yue Y., } \\
\text { Fang P. }\end{array}$ & $\begin{array}{l}\text { Quality management in pellet feed mill based } \\
\text { on statistical process control (SPC). }\end{array}$ & $\begin{array}{l}\text { Am. Soc. of Agric. } \\
\text { and Biol. Engin. Ann. } \\
\text { Internat. Meeting }\end{array}$ & 2016 & 0 \\
\hline 5 & $\begin{array}{l}\text { Tenorio C., Moya R., } \\
\text { Filho M.T., Valaert J. }\end{array}$ & $\begin{array}{l}\text { Quality of pellets made from agricultural and } \\
\text { forestry crops in costa rican tropical climates. }\end{array}$ & BioResources & 2015 & 6 \\
\hline 6 & $\begin{array}{l}\text { Seo J.-W., Lee E.-S., } \\
\text { Kang C.-Y., et al. }\end{array}$ & $\begin{array}{l}\text { Comparison of quality characteristics of } \\
\text { woodpellet manufactured from Pinus } \\
\text { densiflora S. et Z. and Pinus rigida Mill. }\end{array}$ & $\begin{array}{l}\text { Journal of the Korean } \\
\text { Wood Science and } \\
\text { Technology }\end{array}$ & 2015 & 0 \\
\hline 7 & $\begin{array}{l}\text { Garcia-Maraver A., } \\
\text { Zamorano M., Fernandes } \\
\text { U., et al. }\end{array}$ & $\begin{array}{l}\text { Relationship between fuel quality and gaseous } \\
\text { and particulate matter emissions in a domestic } \\
\text { pellet-fired boiler. }\end{array}$ & Fuel & 2014 & 40 \\
\hline 8 & $\begin{array}{l}\text { Avalle P., Pollitt M.J., } \\
\text { Bradley K., et Al. }\end{array}$ & $\begin{array}{l}\text { Development of Process Analytical } \\
\text { Technology (PAT) methods for controlled } \\
\text { release pellet coating. }\end{array}$ & $\begin{array}{l}\text { European Journal of } \\
\text { Pharmaceutics and } \\
\text { Biopharmaceutics }\end{array}$ & 2014 & 6 \\
\hline 9 & $\begin{array}{l}\text { Ahn B.-J., Kim Y.S., } \\
\text { Lee O.-K., et Al. }\end{array}$ & $\begin{array}{l}\text { Wood pellet production using domestic forest } \\
\text { thinning residues and their quality } \\
\text { characteristics. }\end{array}$ & $\begin{array}{c}\text { Journal of the Korean } \\
\text { Wood Science and } \\
\text { Technology } \\
\end{array}$ & 2013 & 2 \\
\hline 10 & $\begin{array}{l}\text { Toscano G., Riva G., } \\
\text { Foppa Pedretti E., et Al. }\end{array}$ & $\begin{array}{l}\text { Investigation on wood pellet quality and } \\
\text { relationship between ash content and the most } \\
\text { important chemical elements. }\end{array}$ & $\begin{array}{l}\text { Biomass and } \\
\text { Bioenergy }\end{array}$ & 2013 & 24 \\
\hline 11 & $\begin{array}{l}\text { Gillespie G.D., Everard } \\
\text { C.D., Fagan C.C., } \\
\text { McDonnell K.P. }\end{array}$ & $\begin{array}{l}\text { Prediction of quality parameters of biomass } \\
\text { pellets from proximate and ultimate analysis. }\end{array}$ & Fuel & 2013 & 16 \\
\hline 12 & $\begin{array}{l}\text { Muntean A., Ivanova T., } \\
\text { Havrland B., et Al. }\end{array}$ & $\begin{array}{l}\text { Particularities of bio-raw material particle } \\
\text { agglomeration during solid fuel pressing }\end{array}$ & $\begin{array}{l}\text { Engineering for Rural } \\
\text { Development }\end{array}$ & 2013 & 0 \\
\hline 13 & $\begin{array}{l}\text { Kirsanovs V., Timma L., } \\
\text { Zandeckis A., } \\
\text { Romagnoli }\end{array}$ & $\begin{array}{l}\text { The quality of pellets available on the market } \\
\text { in latvia: Classification according EN } 14961 .\end{array}$ & $\begin{array}{l}\text { Environ. and Climate } \\
\text { Technologies }\end{array}$ & 2012 & 4 \\
\hline 14 & $\begin{array}{l}\text { Alakangas E., Junginger } \\
\text { M., Van Dam J. et Al. }\end{array}$ & $\begin{array}{l}\text { EUBIONET III - Solutions to biomass trade } \\
\text { and market barriers. }\end{array}$ & $\begin{array}{c}\text { Renew. and } \\
\text { Sustainable Energy } \\
\text { Reviews }\end{array}$ & 2012 & 12 \\
\hline 15 & $\begin{array}{l}\text { Domac J., Benkovit Z., } \\
\text { Šegon V., Ištok I. }\end{array}$ & $\begin{array}{l}\text { Critical factors in developing national pellet } \\
\text { market. }\end{array}$ & Sumarski List & 2011 & 1 \\
\hline 16 & $\begin{array}{l}\text { Peidong Z., Yanli Y., } \\
\text { Yongsheng T., et Al. }\end{array}$ & $\begin{array}{l}\text { Bioenergy industries development in China: } \\
\text { Dilemma and solution. }\end{array}$ & $\begin{array}{c}\text { Renew. and } \\
\text { Sustainable Energy } \\
\text { Reviews }\end{array}$ & 2009 & 89 \\
\hline 17 & $\begin{array}{l}\text { Verma V.K., Bram S., } \\
\text { De Ruyck J. }\end{array}$ & $\begin{array}{l}\text { Small scale biomass heating systems: } \\
\text { Standards, quality labelling and market driving } \\
\text { factors. }\end{array}$ & $\begin{array}{l}\text { Biomass and } \\
\text { Bioenergy }\end{array}$ & 2009 & 54 \\
\hline 18 & $\begin{array}{l}\text { Verma V.K., De Ruyck } \\
\text { J. }\end{array}$ & $\begin{array}{l}\text { Standards for small scale solid biomass heating } \\
\text { systems: A European outlook. }\end{array}$ & ECOS 2008 & 2008 & 0 \\
\hline
\end{tabular}




\section{Conclusão}

No mercado Europeu, devido a suas condições climáticas, utiliza-se péletes para aquecimento residencial, pois o mesmo é mais fácil de manusear e possibilita o uso de equipamentos com alimentação automática, daí a necessidade de se estabelecer, regulamentar e controlar a qualidade deste produto. $\mathrm{O}$ mercado brasileiro é voltado para a indústria e o comércio (padarias, pizzarias, caldeirarias, etc.) onde os briquetes são mais promissores que os péletes. Tais setores carecem de normas de qualidade da biomassa compactada para uso alternativo à lenha.

Por outro lado, a exportação de péletes e briquetes brasileiros depende apenas do cumprimento das exigências dos mercados importadores que já possuem suas normas. Os países Europeus já estabeleceram normas internacionais para controle de qualidade e de nada adianta ao Brasil criar suas próprias normas. Cabe às instituições competentes criar/capacitar laboratórios e profissionais para processar análises e testes padrões de acordo com as normas que atendam as peculiaridades locais e as normas mundiais, possibilitando a certificação de produtores brasileiros para atendimento dos mercados internos e externos.

\section{Referências}

AHN B.-J., KIM Y.S., LEE O.-K., CHO S.-T., CHOI D.H., LEE S.M. Wood pellet production using domestic forest thinning residues and their quality characteristics. Journal of the Korean Wood Science and Technology, 2013.

ALAKANGAS E., JUNGINGER M., VAN DAM J., HINGE J., KERÄNEN J., OLSSON O., PORSÖ C., MARTIKAINEN A., RATHBAUER J., SULZBACHER L., VESTERINEN P., VINTERBÄCK J. EUBIONET III - Solutions to biomass trade and market barriers. Renewable and Sustainable Energy Reviews, 2012.

ANEEL - Agencia Nacional de Energia Elétrica. Atlas de Energia Elétrica - 3 ${ }^{\text {a }}$ ed., Brasília: 2008.

ABNT - Associação Brasileira de Normas Técnicas. NBR 6922. Carvão vegetal - Ensaios físicos Determinação da massa específica - Densidade a granel. Rio de Janeiro, 1981.

AUSTRIAN STANDARDS INSTITUTE. ÖNORM EN 14961-2. Solid biofuels - Fuel specifications and classes - Part 2: Wood pellets for non-industrial use. Draft. Wien, 2010.

AVAlle P., POLlitT M.J., BRADLEY K., COOPER B., PEARCE G., DJEMAI A., FITZPATRICK S. Development of Process Analytical Technology (PAT) methods for controlled release pellet coating. European Journal of Pharmaceutics and Biopharmaceutics, 2014.

BRUNEROVA A., IVANOVA T., BROZEK M. Mechanical durability of digestate briquettes mixed with mineral additives. Engineering for Rural Development, 2016.

BRUNEROVÁ A., PECEN J., BROŽEK M., IVANOVA T. Mechanical durability of briquettes from digestate in different storage conditions. Agronomy Research, 2016. 
CARASCHI J.C. e GARCIA, D.P. A expansão do mercado de pellets de madeira: Painel Florestal, fevereiro de 2012. http://www.painelflorestal.com.br/.../a-expansao-do-mercado-de-pellets-demade...Acessado em 12 de julho de 2017.

CORTEZ, L.A.B; LORA, E.E.S.; GOMEZ, E.O. Biomassa para energia. Campinas, São Paulo. Editora da UNICAMP, 2008.

COSTA, H. G. Modelo para webibliomining: proposta e caso de aplicação. Revista da FAE, Paraná, v. 13, n. 1, p. 115-126, 2010.

CUPERTINO, S. A. Pellets de Madeira como uma Alternativa para a Geração Termelétrica no Brasil. Brasília: Núcleo de Estudos e Pesquisas/CONLEG/ Senado, Junho/2017 (Texto para Discussão n 235). www.senado.leg.br/estudos. Acessado em 22 de Novembro de 2017.

DIAS, J. M. S. et al. Produção de briquetes e péletes a partir de resíduos agrícolas, agroindustriais e florestais. Brasília, DF: Embrapa Agroenergia, 2012. 132 p.

DIN CERTCO. Certification scheme wood pellets for use in small furnaces - DINplus. Berlim, Junho de 2015.

DIN CERTCO. Certification scheme wood briquettes. Berlim, Junho de 2015.

EUROPEAN PELLET COUNCIL. A nova norma Europeia para pellets de madeira (EN 14961-2) e a sua implementação através da certificação ENplus. 2014. http://www.cebio.net/web/images/stories/PellCert_flyer.pdf. Acessado em 20 de setembro de 2017.

DEUTSCHES INSTITUT FÜR NORMUNG. DIN 51900: Determining the gross calorific value of solid and liquid fuels using the bomb calorimeter, and calculation of net calorific value. Berlin, 2000 .

DOMAC J., BENKOVI, Z., ŠEGON V., IŠTOK I. Critical factors in developing national pellet market. Sumarski List, 2011.

DEUTSCHES PELLETINSTITUT GmbH. Handbook for the Certification of Wood briquettes. Berlim, V 1.0, Janeiro de 2013.

EUROPEAN PELLET COUNCIL; Associação Européia de Biomassa. Manual EN plus, parte 1 Considerações Gerais. Bélgica, V 3.0, Agosto de 2015.

EUROPEAN PELLET COUNCIL; Associação Européia de Biomassa. Manual EN plus, parte 3 Requisitos de Qualidade de Pellets. Bélgica, V 3.0, Agosto de 2015.

GARCIA-MARAVER A., ZAMORANO M., FERNANDES U., RABAÇAL M., COSTA M. Relationship between fuel quality and gaseous and particulate matter emissions in a domestic pelletfired boiler. Fuel, 2014. 
GARCIA MARAVER, A.; PEREZ JIMENEZ J. A. Biomass Pelletization: Standards and Production. England: Wit Press, 2015.

GILLESPIE G.D., EVERARD C.D., FAGAN C.C., MCDONNELL K.P. Prediction of quality parameters of biomass pellets from proximate and ultimate analysis. Fuel, 2013.

GOLDEMBERG, J. Biomassa e energia. Química Nova, São Paulo, v. 32, n. 3, p. 582-587, 2009.

HOOD, W. W.;WILSON, C. S. The literature of bibliometrics, scientometrics, and informetrics. Scientometrics, Amsterdam, NL., v.52, n.2, p.291-314, Out. 2001.

IPCC, 2012: Renewable Energy Sources and Climate Change Mitigation. Special Report of the Intergovernmental Panel on Climate Change. [ O. Edenhofer, R. P. Madruga, Y. Sokona, K. Seyboth, P. Matschoss, S. Kadner, T. Zwickel, P. Eickemeier, G. Hansen, S. Schlömer, C. Stechow]. Cambridge University Press, New York, NY, USA, 1088 pp.

KIRSANOVS V., TIMMA L., ZANDECKIS A., ROMAGNOLI F. The quality of pellets available on the market in latvia: Classification according EN 14961 requirements. Environmental and Climate Technologies, 2012.

KRIGSTIN S., WETZEL S., MABEE W., STADNYK S. Can woody biomass support a pellet industry in southeastern Ontario: A case study. Forestry Chronicle, 2016.

LV F., WANG H., KONG D., CHEN X., YUE Y., FANG P. Quality management in pellet feed mill based on statistical process control (SPC). American Society of Agricultural and Biological Engineers Annual International Meeting, ASABE, 2016.

MUNTEAN A., IVANOVA T., HAVRLAND B., POBEDINSKY V., VRANCEAN V. Particularities of bio-raw material particle agglomeration during solid fuel pressing process. Engineering for Rural Development, 2013.

OLIVEIRA, C. M. Demanda de pellets e biomassa no mercado Europeu. Revista da Madeira, Edição n137, Outubro de 2013.

OLIVEIRA, C.M. Wood Pellets Brasil, 2012. http://pt.calameo.com/read/00089539002c2bf637402. Acessado em 12 de julho de 2017.

PEIDONG Z., YANLI Y., YONGSHENG T., XUTONG Y., YONGKAI Z., YONGHONG Z., LISHENG W. Bioenergy industries development in China: Dilemma and solution. Renewable and Sustainable Energy Reviews, 2009.

PELLET FUELS INSTITUTE WEBSITE. http://www.pelletheat.org/joining-the-standards-program. Acessado em 22 de novembro de 2017.

PELLETS HOME WEBSITE. https://www.pelletshome.com/pellets-normen. Acessado em 22 de novembro de 2017. 


\section{Biomedica Brasiliensia}

SEO J.-W., LEE E.-S., KANG C.-Y., KIM S.-B., YOON Y.H., PARK H. Comparison of quality characteristics of woodpellet manufactured from Pinus densiflora S. et Z. and Pinus rigida Mill. Journal of the Korean Wood Science and Technology, 2015.

TENORIO C., MOYA R., FILHO M.T., VALAERT J. Quality of pellets made from agricultural and forestry crops in costa rican tropical climates. BioResources, 2015.

TOSCANO G., RIVA G., FOPPA PEDRETTI E., CORINALDESI F., MENGARELLI C., DUCA D. Investigation on wood pellet quality and relationship between ash content and the most important chemical elements. Biomass and Bioenergy, 2013.

VERMA V.K., BRAM S., DE RUYCK J. Small scale biomass heating systems: Standards, quality labelling and market driving factors - An EU outlook. Biomass and Bioenergy, 2009.

VERMA V.K., DE RUYCK J. Standards for small scale solid biomass heating systems: A European outlook. ECOS, 2008. 